\title{
Effect of Geometrical Parameter Cutting Edge on the Toroidal Forming Surface of a Solid End Mill
}

\author{
Petr Pivkin*1,2,3,4, Ilya Minin 1,2,3,4 \\ ${ }^{1}$ Dept. of Cutting Tools and Shaping Technologies, Moscow State University of Technology “STANKIN”, RU-127055, Moscow, \\ Russia; \\ ${ }^{2}$ Dept. of High-Efficiency Processing Technologies, Moscow State University of Technology “STANKIN”, RU-127055, Moscow, \\ Russia, \\ ${ }^{3}$ Lab. of Micromachining Technologies, Moscow State University of Technology “STANKIN”, RU-127055, Moscow; Russia; \\ ${ }^{4}$ Center of Cognitive Technologies and Machine Vision, Moscow State University of Technology “STANKIN”, RU-127055, Moscow; \\ Russia;
}

\begin{abstract}
Solid end mill with a toroidal forming section are the most productive solutions in the field of processing difficult-to-process materials. The process of forming the cutting geometry of such cutters is performed on grinding machines with CNC with the use of abrasive grinding wheels. The formation of the cutting edge on the toroidal section is carried out by discrete movements of the working bodies of the machine in accordance with the control program. The disadvantage of the stepper drive used in CNC machines is the limited discreteness of the described trajectory resulted in the loss of accuracy when forming radius, arc, spherical and toroidal sections. Loss of accuracy in the formation of elements of the working geometry of a solid end mill can negatively affect the tool life, and the structural strength of the joints of the transition of working surfaces. The study is aimed at identifying the necessary and sufficient number of points that describe the spatial shape of the cutting edge with acceptable loss of accuracy.
\end{abstract}

\section{Inroduction}

The formation of surfaces of parts made of hard-to-work materials, such as heat-resistant nickel steels and stainless alloys, is accompanied by a high power load cause by hardening. In order to structurally increase the strength of the cutting tool, the tops of the teeth are shaped in the form of radius rounding that allows to improve the distribution of power loads [1-4]. In the process of cutting, the radius surface forms a toroidal shaping section, which provides the possibility of machining end, cylindrical and shaped surfaces of various configurations.

Designing milling cutters with a toroidal end mill includes the solution of forming problems consisting in providing the required angular parameters of the cutting geometry. The cutting edge on the toroidal cutting part is formed at the intersection of the front surface of the screw chip groove, the end front surface and the back surface specified by the rear angles $\alpha_{1}$ and $\alpha_{2}$. The shape of the edge depends on the size of the radius forming the toroidal surface, the anterior angle $\gamma$, the section of the constant geometry $\mathrm{S}_{\mathrm{c}}$ and the transition section to the back of the tooth $V_{d}$. Figure 1 shows the key parameters of the chip groove profile.

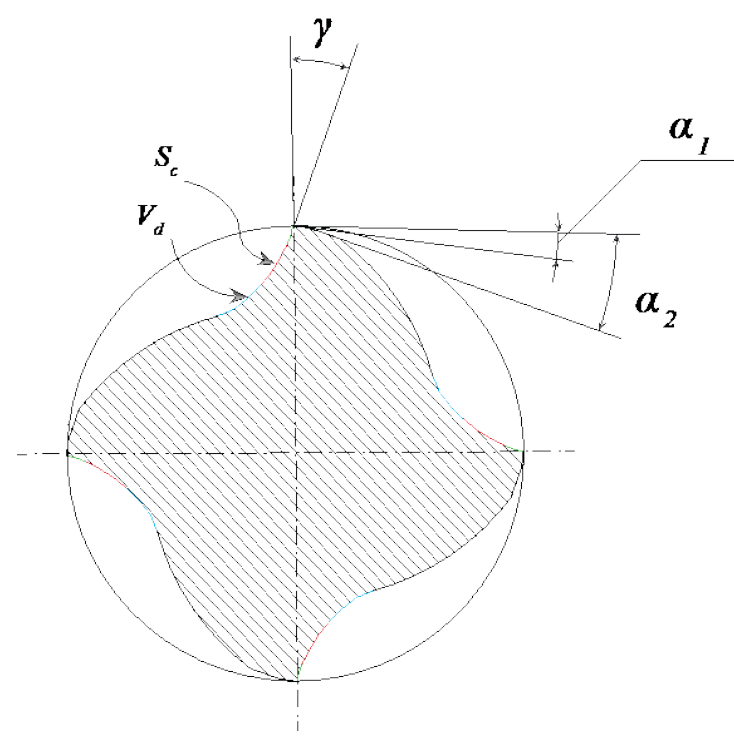

Fig. 1. Parameters of the chip groove profile.

Milling cutters with a toroidal forming surface are produced mainly on CNC grinding machines. Shaping of the front and back surfaces of the tool is performed by grinding abrasive wheels of various configurations suitable for processing specific surfaces. The choice of the most suitable trajectory of the grinding wheel is 
determined by ensuring that the shape of the formed areas and the sharpness of the geometry of the cutting wedge being processed correspond each other.

Stepper motors on the modern grinding machines are used as drive elements that carry out the main movements of the tool and the workpiece. One of the disadvantages of such a system is the restriction on the permissible number of individual movements per unit of time. Exceeding the limit can lead to an interruption of the control program execution or to the skipping of the trajectory stages, which can lead to a violation of the accuracy requirements for the shape being formed. Radius, spherical, arc-shaped and other sections of the trajectory that have curvature are approximated in accordance with the accepted limit on the throughput of the CNC system. As a result of approximating, a loss of accuracy in shaping the working surfaces of the tool appears, which can lead to a distortion of the geometry of the cutting edge that adversly affects the accuracy and performance of the entire cutting tool [5-50].

\section{Results and Discussion}

Defining the necessary and sufficient number of points that gives shape to the spatial line of the cutting edge it is possible to reduce the load on stepper motor tool grinding machine, determining the location of these points can reduce the overall form error of the cutting edge.

At the first stage of the study, a three-dimensional model of a solid end mill with a toroidal forming surface was developed. The model was based on the working surface of the torus, defined using parameterization elements, expressed in the established functional dependencies between the parameters of the end mill and the dimensions of the forming and guiding toroidal surface. The equation of the toroidal generating surface in parametric form is presented as equation 1 .

$$
T(\varphi, \psi)=\left\{\begin{array}{c}
x(\varphi, \psi)=\left(\left(\frac{D}{2}-r\right)+r \cdot \cos (\psi)\right) \cos (\varphi) \\
y(\varphi, \psi)=\left(\left(\frac{D}{2}-r\right)+r \cdot \cos (\psi)\right) \sin (\varphi) \\
z(\varphi, \psi)=r \cdot \sin (\psi)
\end{array}\right.
$$

$\varphi \in[0,2 \pi), \psi \in[-\pi, \pi]$,

where $\mathrm{D}$ is the diameter of the cutting part, $\mathrm{r}$ is the radius at the top of the tooth.

In [10.1051 / epjconf/201922405001], the process of mathematical modeling of the working part of a solid end ceramic cutter with a toroidal forming surface is described in detail. The shape of the cutting edge is functionally related to the sections of the front surface, rear surfaces and the section of the undercut formed at the intersection of the front end surface and the screw chip groove. The sharpening ensures that the front angle on the cutting part is constant, which best affects the distribution of the power load during the cutting process.

Nodal points were formed on the toroidal surface, defining the shape and location of the cutting edge on the studied area. Each nodal point $\mathrm{N}_{\mathrm{i}} \in(\mathrm{T})$ was located with a uniform step in the first quarter of the generating circle with radius $r$. Figure 2 shows a schematic isometric image of a toroidal surface with nodal points located on it.

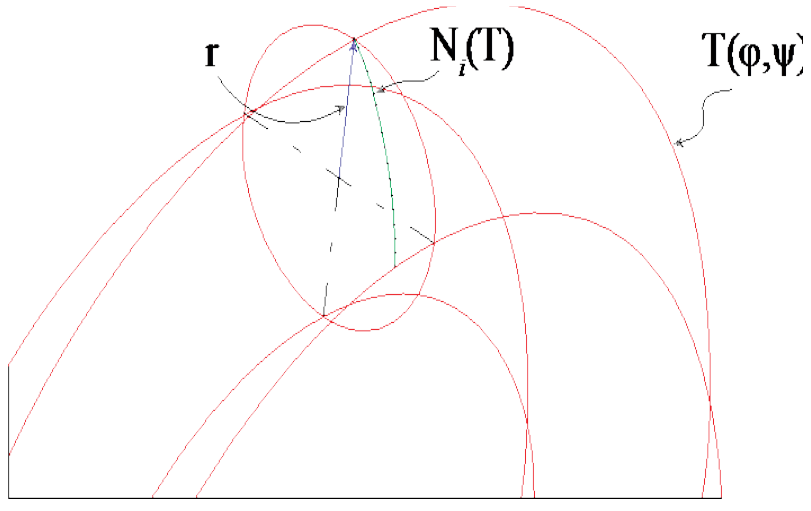

Fig. 2. Toroidal surface with nodal points located on it.

In order to determine the necessary and sufficient number of nodal points, it was necessary to exclude them from the general series with different frequency. By measuring the degree of deviation of the new cutting edge formed between the remaining nodal points, you can determine the degree of influence of both a specific point and a section of the arc formed by a circle on the shape of the cutting edge. Table 1 shows the results of the study.

Table 1. result of measuring the deviation of the cutting edges from the nominal one.

\begin{tabular}{|c|c|c|c|c|c|c|c|c|c|}
\hline & Edge 2 & Edge 3 & Edge 4 & Edge 5 & Edge 6 & Edge 7 & Edge 8 & Edge 9 & Edge 10 \\
\hline Point & Error & Error & Error & Error & Error & Error & Error & Error & Error \\
\hline$\overline{0}$ & 0 & 0 & 0 & 0 & 0 & 0 & 0 & 0 & 0 \\
\hline 1 & 0,04802 & 0,0991 & 0,13505 & 0,18739 & 0,21695 & 0,30316 & 0,30731 & 0,33388 & 0,37371 \\
\hline 2 & 0 & 0,04687 & 0,09069 & 0,15345 & 0,19337 & 0,0378 & 0,30932 & 0,3413 & 0,40362 \\
\hline 3 & 0,01031 & 0 & 0,03864 & 0,09854 & 0,14283 & 0,2655 & 0,27245 & 0,30606 & 0,38422 \\
\hline 4 & 0 & 0,01967 & 0 & 0,04335 & 0,08761 & 0,2183 & 0,22138 & 0,25627 & 0,34226 \\
\hline 5 & 0,0035 & 0,0142 & 0,01442 & 0 & 0,0334 & 0,15725 & 0,16798 & 0,20113 & 0,28873 \\
\hline 6 & 0 & 0 & 0,00571 & 0,02545 & 0 & 0,10429 & 0,11706 & 0,14681 & 0,23048 \\
\hline 7 & 0,03358 & 0,05322 & 0,04326 & 0,09274 & 0,07911 & 0 & 0,01285 & 0,03721 & 0,10978 \\
\hline 8 & 0 & 0,02926 & 0 & 0,06624 & 0,05923 & 0,01312 & 0 & 0,01397 & 0,06937 \\
\hline 9 & 0,00476 & 0 & 0,03314 & 0,03254 & 0,02469 & 0,01386 & 0,00139 & 0 & 0,03257 \\
\hline 10 & 0 & 0,03843 & 0,05813 & 0 & 0,01832 & 0,00374 & 0,009 & 0,0046 & 0 \\
\hline 11 & 0,04802 & 0,0239 & 0,02081 & 0,07498 & 0,03772 & 0,08444 & 0,07106 & 0,10009 & 0,12711 \\
\hline
\end{tabular}




\begin{tabular}{|c|c|c|c|c|c|c|c|c|c|}
\hline & Edge 2 & Edge 3 & Edge 4 & Edge 5 & Edge 6 & Edge 7 & Edge 8 & Edge 9 & Edge 10 \\
\hline Point & Error & Error & Error & Error & Error & Error & Error & Error & Error \\
\hline 12 & 0 & 0 & 0 & 0,05563 & 0 & 0,05834 & 0,04318 & 0,08825 & 0,14616 \\
\hline 13 & 0,00082 & 0,00273 & 0,02323 & 0,03867 & 0,02716 & 0,02899 & 0,00914 & 0,0695 & 0,15613 \\
\hline 14 & 0 & 0,00279 & 0,04854 & 0,02102 & 0,04591 & 0 & 0,02834 & 0,04464 & 0,15539 \\
\hline 15 & 0,04948 & 0 & 0,07458 & 0 & 0,05928 & 0,02579 & 0,06617 & 0,01452 & 0,14219 \\
\hline 16 & 0 & 0,0785 & 0 & 0,07335 & 0,0298 & 0,04965 & 0 & 0,07929 & 0,21396 \\
\hline 17 & 0,00399 & 0,04295 & 0,0239 & 0,04033 & 0,0188 & 0,0233 & 0,02564 & 0,04035 & 0,16859 \\
\hline 18 & 0 & 0 & 0,04746 & 0,00063 & 0 & 0,00797 & 0,04581 & 0 & 0,10398 \\
\hline 19 & 0,0339 & 0,04561 & 0,07228 & 0,04604 & 0,03433 & 0,04765 & 0,06706 & 0,03912 & 0,01554 \\
\hline 20 & 0 & 0 & 0 & 0 & 0 & 0 & 0 & 0 & 0 \\
\hline $\begin{array}{l}\text { Summ } \\
\text { Error }\end{array}$ & 0,23638 & 0,49723 & 0,72984 & 1,05035 & 1,10851 & 1,44315 & 1,77514 & 2,11699 & 3,46379 \\
\hline $\begin{array}{l}\text { Mid } \\
\text { Error }\end{array}$ & 0,023638 & 0,038248 & 0,048656 & 0,065647 & 0,069282 & 0,084891 & 0,10442 & 0,124529 & 0,192433 \\
\hline $\begin{array}{l}\text { Max } \\
\text { Error }\end{array}$ & 0,04948 & 0,0991 & 0,13505 & 0,18739 & 0,21695 & 0,30316 & 0,30932 & 0,3413 & 0,40362 \\
\hline $\begin{array}{l}\text { Crit. } \\
\text { Point }\end{array}$ & 15 & 1 & 1 & 1 & 1 & 1 & 2 & 2 & 2 \\
\hline $\begin{array}{l}\text { Critical } \\
\text { Point } \\
\text { Number }\end{array}$ & 10 & 13 & 15 & 16 & 16 & 17 & 17 & 17 & 18 \\
\hline
\end{tabular}

After analyzing the results, it can be concluded that the transition to the cutting edge at the end section has the greatest impact. The degree of error increases with a decrease in the number of nodal points, but for results $3-5$ deviations have a periodic form, which can be compensated by shifting the nodal points from a given position. In charts 1 to 3 presents the deviations of the results of 3 to 5 , respectively.

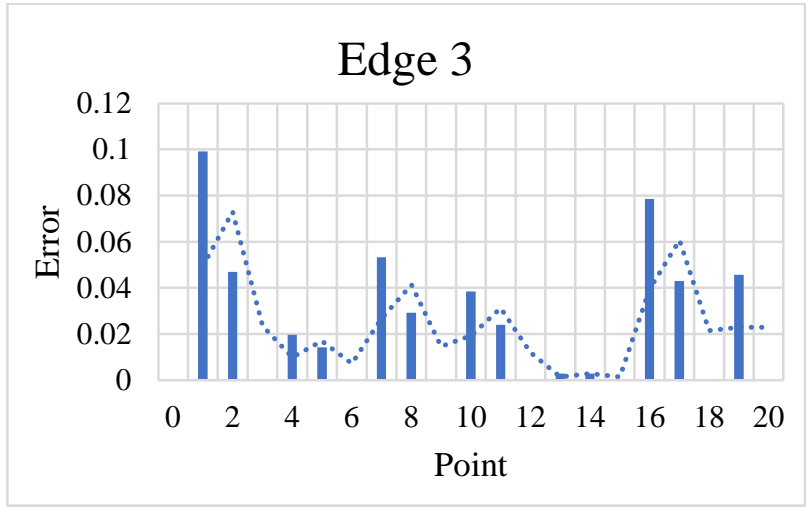

Graph 1. Deviations of grid points from the nominal for a result of 3 .

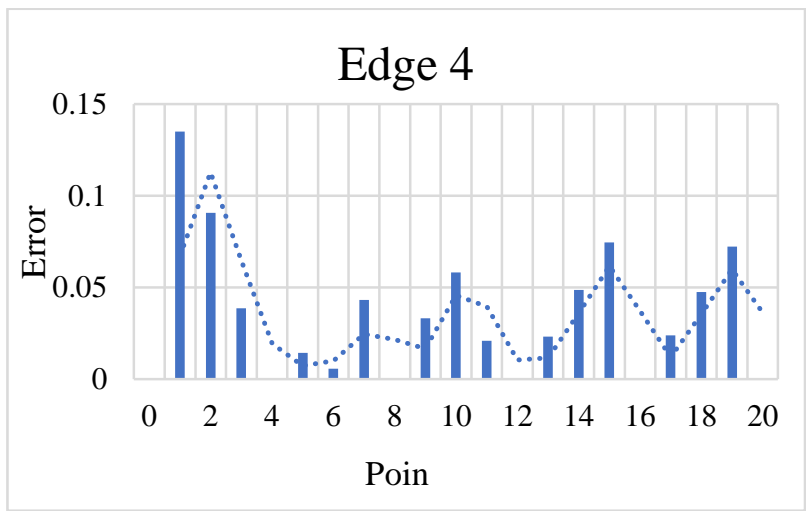

Graph 2. Deviations of the nodal points from the nominal ones for result 4.

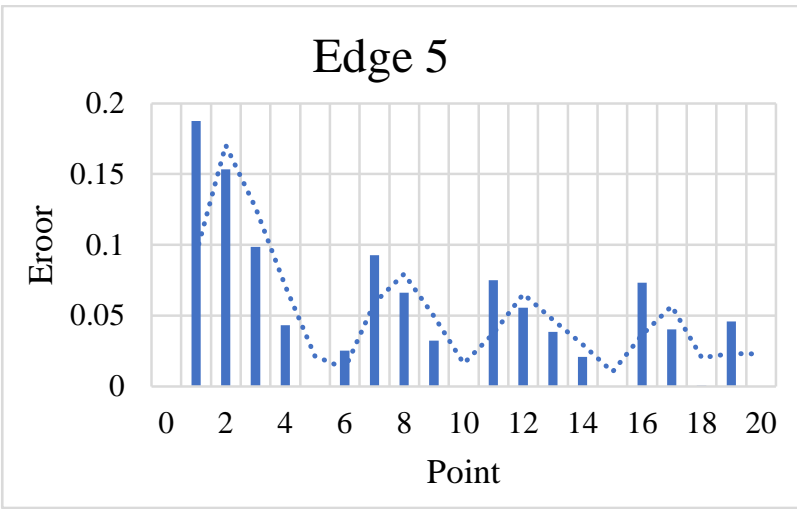

Graph 3. Deviations of nodal points from nominal ones for result 5.

By making adjustments at the most critical nodal points, you can improve the accuracy of the cutting edge shape. Thus, it is possible to reduce the required number of nodal points for setting the spatial line of the cutting edge, which helps to reduce the necessary approximations on CNC grinding and grinding machines when preparing the control program.

\section{Conclusion}

A model of the end mill with toroidal section and the cutting edge lying on it was developed. By sifting out, with different frequency, the nodal points that define the shape of the spatial line of the cutting edge, it was found that there is a periodicity in the resulting deviations that can be compensated and, thus, the loss of accuracy of the cutting edge shape from nominal as well as the number of approximations on CNC machines can be significantly reduced. Thus, it is possible to significantly reduce the load on the stepper motor and, at the same time, allow for only a small reduction in the accuracy of the edge being formed. 


\section{Acknowledgments}

This research was funded by Ministry of Science and Higher Education of the Russian Federation, Grant No. 0707-2020-0031. This work was carried out using equipment provided by the Center of Collective Use of MSUT "STANKIN".

\section{References}

1. T. Chen, X. Liu, C. Wang et al., Int J Adv Manuf Technol 80, 567-579 (2015).

2. S. Kim, Key Eng. Mater. 96, 33-80 (1994).

3. B. Bitterlich, S. Bitsch, K. Friederich, J. Eur. Ceram. Soc. 28(5), 989-994 (2008).

4. T. Zlámal, J. Hajnyš, J. Petrů, I. Mrkvica, Adv. Sci. Technol. Res. J. 12(1), 236-243 (2018).

5. S.N. Grigoriev, V.A. Grechishnikov, M.A. Volosova, et al., Russ. Eng. Res. 40, 79-82 (2020).

6. Ji Wei, L. Xianli, W. Lihui, M. Yue, Wu Xuefeng, J. Manuf. Process 19, 205-211 (2015).

7. G.M. Martinov, P.A. Nikishechkin, A.S. Grigoriev, N.Yu. Chervonnova, Autom. Remote. Control. 80(3), 584-591 (2019).

8. S.N. Grigoriev, G.M. Martinov, Proc. CIRP 14, 517-522 (2014).

9. S.N. Grigoriev, G.M. Martinov, Proc. CIRP 41, 858-863 (2016).

10. F. Molaiekiya, M. Aramesh, S.C. Veldhuis, Wear. 203191, 446-447 (2020).

11. L. Tan, C. Yao, J. Ren, D. Zhang, Int. J. Adv. Manuf. Technol. 88, 2589-2602 (2016).

12. J. Hsieh, Y. Tsai, Int. J. Adv. Manuf. Technol. 29, 912-921 (2006).

13. V.V. Kuzin, S.N. Grigoriev, M.Yu. Fedorov, J. Frict. Wear. 36(1), 40-44 (2015).

14. R. Alexander, K. Iyas, K. Andreas, J. Eur. Ceram. Soc. 36(3), 705-717 (2016).

15. V.V. Kuzin, S.N. Grigor'ev, M.A. Volosova, Refract. Ind. Ceram. 54, 376-380 (2014).

16. L. Xing, D. Zhaoqian, Jianxin, Tran Tech Publications, (1995).

17. Z. Wang, Liu, Int. J. Refract. Hard. Met. 55, $24-$ 32 (2016).

18. N.V. Kolesov, Y.E. Petukhov, Russ. Eng. Res. 27, 812-814 (2007).

19. A. Metel, V. Bolbukov, M. Volosova, S. Grigoriev, Yu. Melnik, Surf. Coat. Technol. 225, 34-39 (2013).

20. V.V. Kuzin, S. Grigoriev, Appl. Mech. Mater. 486, 32-35 (2013).

21. L. Xiong, B. Li, Int. J. Adv. Manuf. Technol. 82, 889-900 (2016).

22. A.S. Metel, S.N. Grigoriev, Y.A. Melnik, et al., Instrum. Exp. Tech. 55, 288-293 (2012).
23. V.A. Grechishnikov, S.N. Grigoriev, P.M. Pivkin, A.V. Isaev, M.A. Volosova, P.Yu. Peretyagin, Russ. Eng. Res. 39, 1084-1087 (2019).

24. V. Grechishnikov, S. Grigoriev, P. Pivkin, M. Volosova, A. Isaev, D. Nikitin, I. Minin, EPJ Web Conf. 224(05001) (2019).

25. Z. Wang, Liu, Int. J. Refract. Metals Hard Mater. 55, 24-32 (2016).

26. Y.E. Petukhov, N.V. Kolesov, S.Y. Yurasov, Russ. Eng. Res. 34, 374-380 (2014).

27. Y.E. Petukhov, A.A. Vodovozov, Russ. Eng. Res. 35, 670-673 (2014).

28. S.C. Von, M. Stoetzer, M. Ruecker, M. Wagner, P. Schumann, N.C. Gellrich, Int. J. Oral. Maxillofac. Implants. 29(4), 942-948 (2014).

29. R.S. Khmyrov, S.N. Grigoriev, A.A. Okunkova, A.V. Gusarov, Phys. Procedia 56, 345 (2014)

30. S.N. Grigoriev, D.A. Masterenko, V.I. Teleshevskii, P.N. Emelyanov, Meas. Tech, 55(11), 1311 (2013)

31. V. Krishnaraj, S. Samsudeensadham, R. Sindhumathi, P. Kuppan, Proc. Eng. 97, 251-257 (2014).

32. L. Berglind, E. Ozturk, Springer, 57-93 (2019).

33. B.A. Oluwamayokun, S. Wei-Ming, H.W. Pihua, Mach. Sci. Technol. 16(1), 111-130 (2012).

34. T. Matsumura, T. Furuki, E. Usui, LEM21 2003, 783-788 (2003).

35. S.P. Radzevich, M\&C Publishers, California, San Rafael (2008).

36. S.P. Radzevich, CRC Press, Boca Raton Florida, 738 (2014).

37. S.N. Grigoriev, M.A. Volosova, A.A. Okunkova, S.V. Fedorov, K. Hamdy, P. A. Podrabinnik, A.N. Porvatov, J. Manuf. Mater. Process., 4(3), 96 (2020).

38. P.M. Pivkin, A.B. Nadykto, V.A. Grechishnikov, M.A. Volosova, I.V. Minin, S.N. Grigoriev, Proc. SPIE 11540, 115401G (2020).

39. S.N. Grigoriev, V.A. Grechishnikov, M.A. Volosova, X. Jiang, P.M. Pivkin, IOP Conf. Ser.: Mater. Sci. Eng. 971, 022065 (2020).

40. P.M. Pivkin, V.A. Grechishnikov, A.A. Ershov, A.B. Nadykto, Proc. SPIE 11540, 1154014 (2020).

41. Wei-Fang, C. Wei-Ya, J. Mater. Process. Technol. 121(2-3), 217-225 (2002).

42. D.S. Rechenko, A.Y. Popov, K.V. Averkov, V.A. Sergeev, Russian Engineering Research, 32(5-6), 511 - 512 (2012)

43. Q. Guo, Bo Zhao, Yan Jiang, Wu. Zhao, Precis. Eng. 51, 659-681 (2018).

44. A.V. Gusarov, S.N. Grigoriev, M.A. Volosova, Y.A. Melnik, A. Laskin, D.V. Kotoban, A.A. Okunkova, J. Mater. Process. Technol. 261, 213 (2018). 
45. A. Kovalev, P.A. Nikishechkin and A.S. Grigoriev, ICIEAM - 2017, 1-4 (2017).

46. K. Vinod, A. Eakambaram, A. Arivazhagan, Proc. Eng. 97, 1237-1246 (2014).

47. B. Bergmann, B. Denkena, T. Grove, et al., Int. J. Precis. Eng. Manuf. 20, 37-44 (2019).

48. M. Volosova, S. Grigoriev, A. Metel, A. Shein, Coatings, 8, 287, (2018)

49. M. Tiffe, R. Aßmuth, J. Saelzer, et al., Prod. Eng. Res. Devel. 13, 459-467 (2019).

50. B. Denkena, D. Biermann, CIRP Annals 63(2), 631-653 (2014). 